\title{
Crystallinity changes and mechanical properties of syndiotactic 1,2-polybutadiene under plastic deformation
}

\author{
A. R. Khamidullin ${ }^{1}$, Yu. A. Lebedev ${ }^{2}$, R. R. Kinzyabulatov ${ }^{2, \dagger}$, D. V. Gunderov ${ }^{2}$ \\ †kinzyabulatovrr@mail.ru \\ ${ }^{1}$ Bashkir State University, 32 Zaki Validi St., 450076, Ufa, Russia \\ ${ }^{2}$ Institute of Molecule and Crystal Physics Ufa Research Center of RAS, 151 pr. Oktaybrya, 450075, Ufa, Russia
}

In the present paper the influence of uniaxial tension and severe plastic deformation (SPD) on the structure and physicomechanical properties of syndiotactic 1,2-polybutadiene (SPB), a polymer having thermoplastic properties, have been studied. Test specimens were prepared from commercial grade RB830 polymer (JSR Corp., Japan) with a weight-averaged molecular mass of $1.2 \cdot 10^{5} \mathrm{~g} / \mathrm{mol}$, the degree of crystallinity of $29 \%$ and syndiotactic content of $85-90 \%$. Using X-ray diffractometry and differential scanning calorimetry (DSC) it has been found that in conditions of simple uniaxial tension the crystallinity of SPB at small, less than $250 \%$, elongations increases slightly from $32 \%$ to $37 \%$. With further tension, the sample does not change practically the degree of crystallinity. At deformations of 600 to $650 \%$ the SPB samples lose their transparency and attain a milky-white color that presumably is due to the formation of a new structural state called «milk phase» (mph) in the polymer under deformation. This structural transition does not have any influence on further deformation modes and the resulting structure and color of the sample are maintained after the stress release. When using the technique of severe plastic deformation by means of torsion straining under high pressure on Bridgman anvils, SPB samples also attain a milky color, but become fully amorphous. They undergo a completely lose of elasticity, sharply decrease of density and become brittle. The nature of this difference when using two deformation techniques is discussed. During uniaxial tension, the change of polymer properties occurs due to the reorientation of macromolecules, while SPD apparently results in the rupture of carbon-carbon bonds.

Keywords: syndiotactic 1,2-polybutadiene, thermoelastoplast, plastic deformation, crystallinity.

\section{Изменение степени кристалличности и механические свойства синдиотактического 1,2-полибутадиена при интенсивной пластической деформации}

\author{
Хамидуллин А. Р. ${ }^{1}$, Лебедев Ю. А. ${ }^{2}$, Кинзябулатов Р. Р. ${ }^{2 \dagger}$, Гундеров Д. В. ${ }^{2}$ \\ ${ }^{1}$ Башкирский государственный университет, ул. Заки Валиди 32, 450076, Уфа, Россия \\ ${ }^{2}$ Институт физики молекул и кристаллов УНЦ РАН, пр. Октября 151, 450075, Уфа, Россия
}

В настоящей работе исследовалось влияние одноосного растяжения и интенсивной пластической деформации (ИПД) на структуру и физико-механические свойства синдиотактического 1,2-полибутадиена (СПБ) - полимера, обладающего свойствами термоэластопласта. Испытательные образцы готовились из коммерческого полимера марки RB830 со среднемассовой молекулярной массой $1.2 \cdot 10^{5}$ г/моль, степенью кристалличности 29\% и синдиотактичностью 85 -90\%. Методами рентгеновской дифрактометрии и дифференциальной сканирующей калориметрии (ДСК) установлено, что в условиях простого одноосного растяжения степень кристалличности СПБ при небольших удлинениях до $250 \%$ незначительно возрастает с $32 \%$ до $37 \%$. При дальнейшем удлинении образца степень кристалличности почти не меняется. При деформации до 600-650\% образцы СПБ теряют прозрачность и приобретают молочно-белую окраску, что, предположительно, связано с формированием в полимере при деформации нового структурного состояния, названного «milk phase» (mph). Данный структурный переход не оказывает какого-либо влияния на режимы дальнейшей деформации, а возникающая структура и цвет образца сохраняются при сбросе напряжения. При использовании техники интенсивной пластической деформации - кручение под высоким давлением на наковальнях Бриджмена образцы СПБ также приобретают молочно-белую окраску, но при этом становятся полностью аморфными. У полимера происходит резкое уменьшение плотности, он полностью теряет эластичность и становиться хрупким. Обсуждается природа такого различия при использовании двух методов деформации. При одноосном растяжении полимера изменение свойств происходит из-за переориентации макромолекул, а при ИПД, по-видимому, из-за разрыва углерод-углеродных связей.

Ключевые слова: синдиотактический 1,2-полибутадиен, термоэластопласт, пластическая деформация, степень кристалличности. 


\section{1. Введение}

В последние годы интенсивно развивается производство и применение термоэластопластов - синтетических полимеров, которые при обычных температурах обладают свойствами эластомеров, а при повышенных - размягчаются подобно термопластам. К числу таких материалов относится и сравнительно новый полимер довольно простого строения - синдиотактический 1,2-полибутадиен (СПБ) [1]. Структура СПБ состоит из двух микроскопических фаз - одна аморфная и легко деформируемая, а вторая - жесткая, кристаллическая, выполняющая функцию связи между эластичными блоками. Содержание кристаллической фазы зависит от стереорегулярности полимера и может достигать 85 - 90\% [2 -4]. Это своеобразное «армирование» аморфного полимера нанокристаллитами и придает данному полимеру свойства термоэластопласта Регулируя в условиях синтеза степень кристалличности, можно в широких пределах менять строение СПБ и, следовательно, спектр его физико-механических свойств.

С другой стороны, одной из важнейших базовых технологий производства изделий из термопластичных материалов является процесс горячего формования, в котором полимер подвергается большим деформациям. Получаемый при этом набор микроскопических молекулярных характеристик полимера - степень кристалличности, распределение кристаллитов по ориентациям и степень запутанности полимерной цепи, существенным образом зависит от параметров процесса формования - температуры, степени и скорости деформации [5]. Варьируя их можно целенаправленно управлять как микроструктурой, так и функциональными свойствами материала.

Принято считать, что при небольших деформациях степень кристалличности полимеров снижается, но с ростом степени деформации увеличивается, что связано с удлинением и ориентацией макромолекулярных цепей в направлении деформации. Причем модификация кристаллической фазы и аморфной фазы при деформации могут происходить различным образом. Множество исследований посвящено выяснению связи между эволюцией молекулярного порядка при деформации, прежде всего, в кристаллической части полимера, и основными микроскопическими деформационными механизмами (см., например, [6-8]).

В настоящей работе, на примере синдиотактического 1,2-полибутадиена, изучены механические свойства частично-кристаллических полимеров, подвергнутых пластической деформации. Особое внимание обращено на изменение степени кристалличности в образцах СПБ после деформации растяжением и после интенсивной пластической деформации (ИПД) кручением под высоким давлением.

\section{2. Образцы для исследования и методика эксперимента}

В качестве объекта исследований использовали СПБ марки RB830 (JSR Corp., Япония) со среднечисловой мо- лекулярной массой $\mathrm{M}_{\mathrm{n}} \sim 1.2 \cdot 10^{5}$, содержанием 1,2 звеньев $93 \%$, синдиотактичностью $~ 85$ - 90\%, и степенью кристалличности около $30 \%$. Образцы готовились в виде стандартных двусторонних лопаток с рабочей частью $25 \times 4$ мм и толщиной $1.0 \pm 0.2$ мм. Лопатки вырубались из полимерного полотна, полученного трехступенчатым каландрованием при температуре $140^{\circ} \mathrm{C}$. Одноосное растяжение лопаток проводили на испытательной машине «ZM-40» (Германия) с постоянной скоростью $6.7 \times 10^{-5} \mathrm{M} / \mathrm{c}$. Для нагревания лопаток в процессе деформирования использовалась специальная (lab-made) термокамера из фольгоизолона, в которую феном нагнетался теплый воздух. Температура внутри камеры регулировалась контроллером на базе ПИД-регулятора TPM101 (ОВЕН, Россия) с точностью $2-4^{\circ} \mathrm{C}$. Интенсивная пластическая деформация кручением под высоким давлением (КВД) проводилась на установке «Скрудж-200» (ИФПМ УГАТУ) при гидростатическом давлении до 4 ГПа с числом оборотов $n$ до 4 . В результате подготовлены образцы в форме дисков диаметром $D \sim 20$ мм и толщиной $h$ порядка 1 мм. Для оценки степени сдвиговой деформации $\gamma$ при реализации метода кручения применялась формула [9] $\gamma=2 \pi R n / h$, где $R$ - расстояние от центра образца - диска. Рентгеноструктурные данные получены с помощью дифрактометра Bruker D8 Advance (Германия). При съемке использовалось фильтрованное рентгеновское излучение $\mathrm{CuK}_{\alpha 1}$ (0.1540598 нм), степень кристалличности СПБ оценивалась по методу [10]. Температуры стеклования $\left(T_{c}\right)$ и плавления $\left(T_{m}\right)$ полимерных образцов измеряли методом дифференциальной сканирующей калориметрии (ДСК) на приборе DSC-1 («Mettler Toledo») при скорости нагрева 10 град/мин в атмосфере воздуха.

\section{3. Механические и структурные свойства СПБ}

Зависимость напряжения от удлинения $(\sigma-\varepsilon)$ исходного СПБ марки RB830 (рис.1, кривая 1) является типичной для этого класса полимеров: предел текучести > МПа, предел прочности 21 МПа [3,11,12]. На деформационной кривой $\sigma-\varepsilon$ хорошо идентифицируются три области: (i) область упругой деформации $(\varepsilon<100 \%)$, (ii) область вынужденной эластичности при удлинениях $\varepsilon \sim 100-600 \%$, когда полимер ведет себя подобно каучуку, а природа такой высокой эластичности связана с распрямлением под влиянием нагрузки свернутых гибких полимерных цепей и переориентацией кристаллитов, (iii) область выше $\varepsilon>650 \%$, которая отвечает удлинению переориентированного образца как целого, причем величина деформации на этом участке больше, чем в первой области.

Было обнаружено, что в зоне точки D, соответствующей деформации 600-650\%, образец СПБ теряет прозрачность и приобретает молочно-белую окраску, что связано с формированием при деформации нового состояния, названного «milk phase» $(m p h)$ [13]. Важным является то, что данный структурный переход не оказывает какого-либо влияния на режимы дальнейшей деформации, а возникающая структура и цвет образца сохраняются при сбросе напряжения. При снятии на- 
пряжения наблюдается небольшой гистерезис, но возникшие деформации сбрасываются без отсутствия крипа (рис.1, вставка), что характеризует трһ как достаточно механически устойчивую к действию нагрузки.

Рассмотрим изменение структурных параметров СПБ марки RB830 при деформации. Типичная рентгенограмма исходного СПБ с указанием индексов основных рефлексов и ее трансформация при деформации образцов приведена на рис. 2.

Из нее следует, что степень кристалличности исходного образца составляет $K_{p}=32 \%$. Кристаллиты образованы сегментами плоской зигзагообразной формы с периодом идентичности по оси $\mathbf{c}=0.51 \mathrm{Hм}$, а сами молекулярные цепи упакованы в орторомбическую ячейку с параметрами: $\mathbf{a}=1.1$ нм и $\mathbf{b}=0.622 \mathrm{нм}$, что хорошо согласуется с известными данными $[2,4,13]$. Как было показано нами ранее [14], деформация СПБ в момент формирования mph сопровождается заметным уменьшением размеров кристаллитов в плоскости $\mathbf{a b}$, размер же нанокристаллов (сегмента) вдоль оси с уменьшается до величин, сравнимых с параметрами элементарной ячейки в этом направлении, и поэтому рефлексы, отвечающие периодичности вдоль направления с, прежде всего (111)/(201), размываются и не регистрируются на рентгенограммах (рис. 2, кривые 2,3). Однако, общая степень кристалличности образца практически не меняется (табл. 1).

Деформация приводит к увеличению внутренней энергии полимера, что проявляется в росте энтальпии образца при его деформировании, фиксируемом методом дифференциальной сканирующей калориметрии (ДСК) [15]. Поэтому чтобы получить дополнительные данные о структурных трансформациях, происходящих при деформации СПБ, было проведено сравнение тепловых балансов при нагревании исходного и деформированных до $\varepsilon \sim 700 \%$ полимерных образцов. На кривой ДСК исходного образца СПБ (рис. 3, кривая 1), как и ожидалось, существует четко регистрируемый перегиб при температуре стеклования $\left(\sim-11^{\circ} \mathrm{C}\right)$ и два эндотермических пика; плавления при $\sim 121^{\circ} \mathrm{C}$ (теплота плавления 11 Дж/г) и более слабый при температурах $\sim 50^{\circ} \mathrm{C}$ - природа которого согласно последним данным $[16,17]$ может быть связана с плавлением несовершенных и дефектных кристаллитов, образованных не стереорегулярными макромолекулами. С ростом степени деформации полимера на кривых ДСК (рис. 3, кривые 2-5) наблюдается заметное повышение температуры стеклования (от $-11^{\circ} \mathrm{C}$ до $-5^{\circ} \mathrm{C}$ ).

Поскольку температура стеклования есть характеристика конформационной подвижности молекулярных цепей, прежде всего в аморфной фазе полимера, повышение температуры стеклования объясняется эффектом вытяжки и нагружением «проходных» полимерных цепей в условиях растяжения. Степень кристалличности СПБ, согласно данным ДСК $\left(K_{\text {дсК }}\right)$ (табл. 1$)$ при небольшой деформации образца (до 250\%) незначительно увеличивается, но при дальнейшем удлинении постепенно уменьшается.

Таким образом, сопоставляя данные рентгеновской дифрактометрии и ДСК можно предположить следующее. При растяжении в образце СПБ начинается

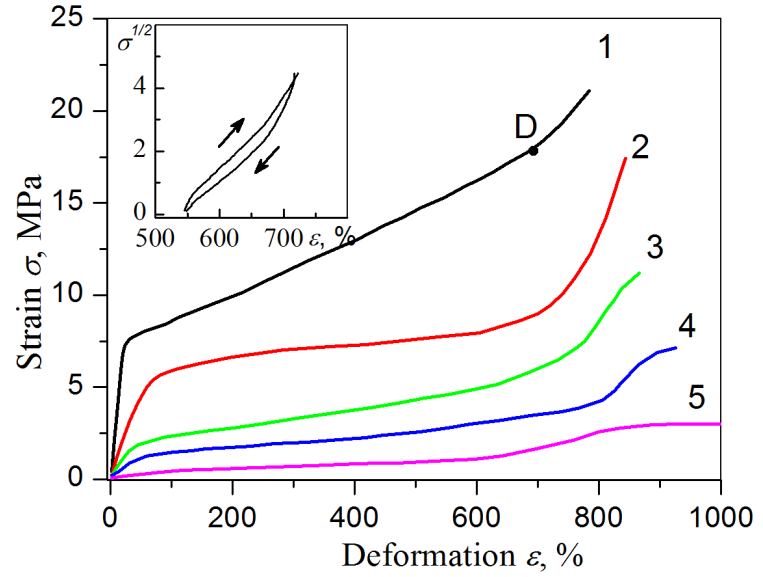

Рис. 1. Деформационные кривые образцов СПБ, измеренные для различных температур: $\sim 20^{\circ} \mathrm{C}$ (1), $30^{\circ} \mathrm{C}$ (2), $40^{\circ}(3)$, $50^{\circ} \mathrm{C}(4), \sim 60^{\circ} \mathrm{C}$ (5). На вставке: деформационная кривая для mph состояния в координатах $\sigma^{1 / 2} \sim \mathcal{E}$ при $20^{\circ} \mathrm{C}$.

Fig. 1. Deformation curves of 1,2 -spb samples measured at temperatures: $\sim 20^{\circ} \mathrm{C}(1), 30^{\circ} \mathrm{C}(2), 40^{\circ} \mathrm{C}(3), 50^{\circ} \mathrm{C}(4), \sim 60^{\circ} \mathrm{C}(5)$. Inset: deformation curve for $\mathrm{mph}$ state at $20^{\circ} \mathrm{C}$ in $\sigma^{1 / 2} \sim \mathcal{\varepsilon}$ coordinates.

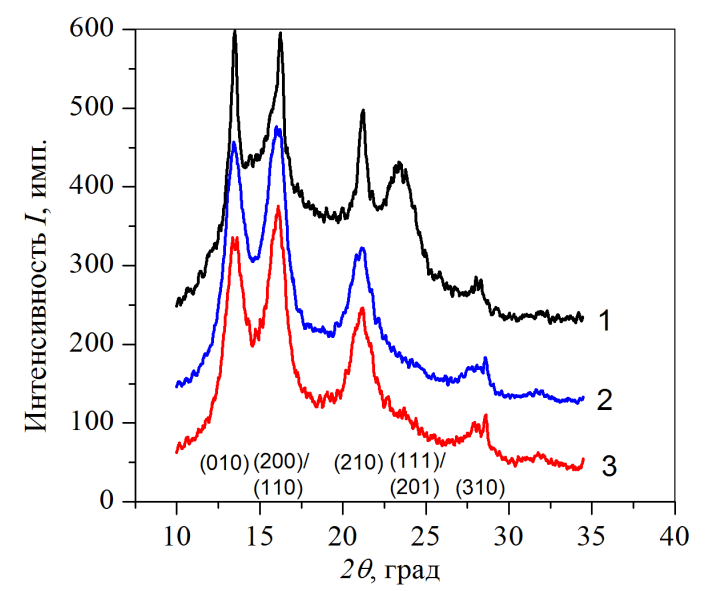

Рис. 2. Рентгеновские дифрактограммы СПБ RB830: исходный образец (1), образец после деформации до $\varepsilon=250 \%$ (2) и до состояния $\mathrm{mph}(\varepsilon=700 \%)$ (3). Приведены индексы $h k l$ основных рентгеновских рефлексов.

Fig. 2. X-ray diffraction patterns of 1,2-spb samples: initial sample (1), samples deformed for $\varepsilon=250 \%(2)$ and $\varepsilon=700 \%$ (mph) (3). $h k l$ indices of main diffraction peaks are shown.

табл. 1. Изменение степени кристалличности $\left(K_{p}, K_{\text {дск }}\right)$, температур стеклования $\left(T_{c}\right)$ и плавления $\left(T_{m}\right)$ СПБ при деформации $(\varepsilon)$.

Table 1. Change in the degree of crystallinity $\left(C_{\mathrm{X} \text {-ray }}, C_{D S C}\right)$, the glass transition temperature $\left(T_{g}\right)$, melting temperature $\left(T_{m}\right)$ of the SPB at deformation $(\varepsilon)$.

\begin{tabular}{|c|c|c|c|c|c|}
\hline$\varepsilon, \%$ & $\begin{array}{c}K_{p}, \% \\
C_{\mathrm{X} \text {-ray }}, \%\end{array}$ & $\begin{array}{c}K_{\text {дCK }}, \% \\
C_{D S C}, \%\end{array}$ & $\begin{array}{c}T_{c},{ }^{\circ} \mathrm{C} \\
T_{g},{ }^{\circ} \mathrm{C}\end{array}$ & $\begin{array}{l}T_{m 1},{ }^{\circ} \mathrm{C} \\
T_{m 1},{ }^{\circ} \mathrm{C}\end{array}$ & $\begin{array}{c}T_{m 2},{ }^{\circ} \mathrm{C} \\
T_{m 1}{ }^{\circ} \mathrm{C}\end{array}$ \\
\hline 0 & 32 & 32 & $-10,8$ & 49,8 & 120,6 \\
\hline 150 & - & 34 & $-10,8$ & 49,4 & 119,5 \\
\hline 250 & 31 & 37 & $-9,4$ & 39,4 & 119,0 \\
\hline 450 & - & 36 & $-6,9$ & 39,0 & 117,6 \\
\hline 700 & 30 & 34 & $-4,9$ & 40,3 & 117,2 \\
\hline
\end{tabular}


масштабная переориентация макромолекул вдоль направления деформации, что приводит к их частичной рекристаллизации и появлению большого числа мелких кристаллитов, что отражается в уширении площади пика при $\sim 121^{\circ} \mathrm{C}$ на кривых ДСК (рис. 3, кривые $2-5$ ). Одновременно, как показывают данные рентгеновского анализа, происходит разрушение уже имеющихся крупных кристаллов, на мелкие, (рис. 2, кривые 2,3) и понижение температур плавления полимера $T_{м}$ (с $\sim 121$ до $\left.117^{\circ} \mathrm{C}\right)$. Вообще говоря, отсутствие корреляции в поведении при деформации кристаллической фазы, установленное методами рентгеновского анализа и ДСК не является неожиданным (см. например, [18]). Возможная причина наблюдаемого различия в поведении - недооценка кристалличности в рентгеновском методе из-за уменьшения вклада от малых кристаллитов, тогда как в ДСК учитываются вклады от всего ансамбля кристаллитов независимо от их размера.

Более существенные изменения наблюдаются для второго менее интенсивного пика при $\sim 50^{\circ} \mathrm{C}$. С повышением степени деформации полимера до $\varepsilon=700 \%$ температура максимума этого пика снижается до $39^{\circ} \mathrm{C}$, а энтальпия процесса уменьшается почти в два раза до 2 Дж/г. Такое поведение может свидетельствовать о том, что данный пик обусловлен плавлением кристаллитов, образованных с участием нестереорегулярных фрагментов макромолекул [19], поскольку для подобных участков в большей степени характерна конформация клубка, и при деформации именно они подвергаются самому большому удлинению, что и приводит к интенсивному разрушению дефектных кристаллов. Симбатное изменение высокотемпературного и низкотемпературного эндотермических пиков с увеличением степени деформации, коррелирующее с понижением степени кристалличности при растяжении, также позволяет связать наличие второго низкотемпературного пика в СПБ с бимодальным распределением кристаллитов по размеру. При этом вторичные кристаллиты располагаются в областях между первичными ламелями и имеют меньшие размеры, а природа такого распределения, возможно, связана с несовершенством стереорегулярности СПБ [17]. Действительно данный образец полимера содержит заметную долю фрагментов атактических последовательностей 1,2-звеньев и сегментов, состоящих из 1,4-транс и 1,4-цис связей, что снижает долю кристаллизующихся молекулярных цепочек СПБ большой длины, необходимых для формирования первичных ламеллярных кристаллитов. Следовательно, разумно предположить, что кроме формирования первичных ламелей, существует возможность образования из этих коротких стереорегулярных цепочек менее стабильных вторичных кристаллитов. Таким образом, вторичные кристаллиты в СПБ могут действовать в качестве основного фактора, обеспечивающего физическую «сшивку», ответственную за упругие свойства полимера.

Для проверки роли вторичных кристаллитов в деформационном поведении полимера были проведены эксперименты при повышенных температурах. С этой

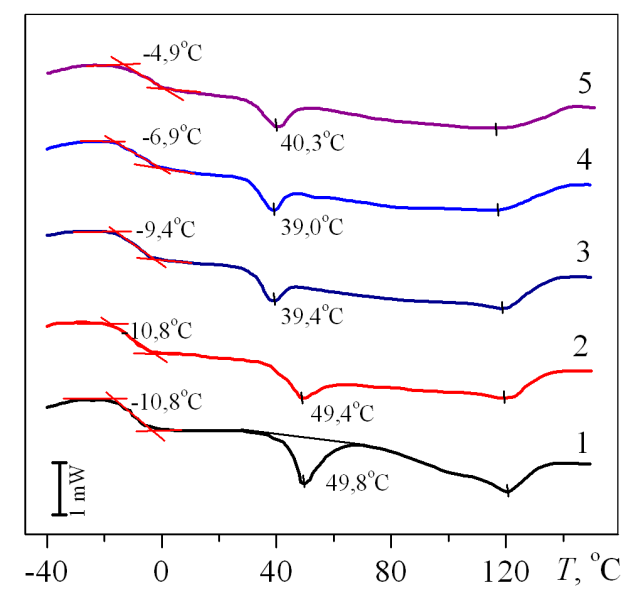

Рис. 3. Экспериментальные кривые ДСК: кривые 1 - исходный СПБ; $2-$ деформированный до $\varepsilon=150 \% ; 3-\varepsilon=250 \%$; $4-\varepsilon=450 \% ; 5-\varepsilon \sim 700 \%$ (mph).

Fig. 3. DSC fusion endotherms of 1,2-spb samples: initial sample (1), samples deformed for $\varepsilon=150 \%$ (2); $\varepsilon=250 \%$ (3); $\varepsilon=450 \%$ (4); $\varepsilon \sim 700 \%$ (mph) (5).

целью были измерены зависимости напряжения от удлинения $(\sigma-\varepsilon)$ исходного СПБ для ряда температур 20,30 , 40,50 и $\sim 60^{\circ} \mathrm{C}$ (рис. 1 ). Было обнаружено, что проведение деформации полимера при повышенных температурах, как и для многих других термоэластопластов, сопровождается увеличением текучести, уменьшением значений модуля упругости (с 1000 до $40 \mathrm{MПа)} \mathrm{и} \mathrm{предела}$ прочности с 20 до 3 МПа. Причем, если при температуpax до $40^{\circ} \mathrm{C}$ в ходе деформации образец на предельных степенях растяжения $\varepsilon \sim 700 \%$ приобретал молочно-белую окраску и наблюдалось формирование так называемой «milk phase», то уже при $T \sim 40^{\circ} \mathrm{C}$ и более образец при растяжении не менял своей окраски вплоть до разрыва и его трансформации в состояние «milk phase» не происходило. Таким образом, в экспериментах по одноосному растяжению образцов СПБ при повышенных температурах подтверждена природа слабоинтенсивного эндотермического пика при температуре $\sim 50^{\circ} \mathrm{C}$ и роль вторичных кристаллитов в формировании «milk phase».

Деформирование полимерного образца в условиях простого растяжения приводило к тому, что при $\varepsilon>800-1000 \%$ образец разрушался. Для достижения больших степеней деформации была применена техника интенсивной пластической деформации кручением под высоким давлением на наковальнях Бриджмена, когда при внешнем давлении порядка 2 ГПа кручение образца на 1 оборот позволяет получить степень деформации $\gamma$ более $1000 \%$, что выше порога появления «milk phase» при растяжении. Оптическая микрофотография такого образца, полученного ИПД КВД, приведена на рис. 4. В процессе кручения образец также как и при растяжении приобрел молочно-белую окраску. Однако он полностью потерял эластичность, стал хрупким и утратил плоскую форму. Кроме того КВД СПБ сопровождается полной потерей кристалличности полимера (см. рис. 4): при давлениях 2 ГПа и степенях деформации более 


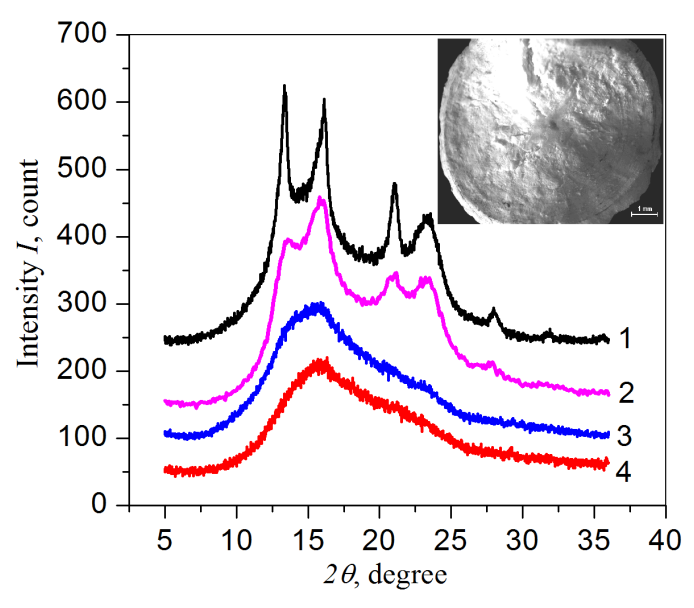

Рис. 4. Рентгеновские дифрактограммы СПБ: исходный образец (1), образец после деформации кручением при давлении 2 ГПа на 0,15 оборота (2), 1 оборот (3) и 4 оборота (4). На вставке: оптическая микрофотография образца СПБ, КВД $P=2$ ГПа, $n=4$ оборота, $T=23^{\circ} \mathrm{C}$.

Fig.4.X-ray diffraction patterns of 1,2-spb samples: initial sample (1), samples deformed at pressure $\sim 2 \mathrm{GPa}$ and for 0,15 turn (2), 1 turn (3) and 4 turn (4). Inset: optical microphotograph of 1,2-spb sample deformed at $\sim 2 \mathrm{GPa}$ for 4 turn, $T=23^{\circ} \mathrm{C}$.

$1000 \%$ - 1 оборота (кривая 3) и 4 оборота (кривая 4) на рентгенограммах следы кристаллической фазы полностью отсутствуют. Она сохраняется лишь при относительно небольших деформациях - порядка 0,15 оборота (кривая 2).

В отличие от случая одноосного растяжения, в условиях одновременного воздействия на образец СПБ высокого давления и сдвиговой деформации, упругая энергия, запасенная полимером под действием высокого давления, при сдвиговой деформации расходуется из-за разрыва С-С химических связей на образование активных свободных радикалов, рекомбинация которых ведет к многочисленным сшивкам макромолекул и интенсивному окислению кислородом воздуха. И, как следствие, резкому снижению эластичности полимера, повышению его хрупкости и пожелтению.

Таким образом, в работе установлено, что деформация СПБ сопровождается разрушением кристалличности. При одноосном растяжении степень кристалличности полимера уменьшается незначительно, но кручение под высоким давлением приводит к полному разрушению кристаллитов. Тем не менее, в обоих случаях образец СПБ приобретает молочно-белую окраску, что свидетельствует об общности процессов протекающих в полимере при различных типах деформации [12]. Характер изменения физических свойств при деформации свидетельствует о том, что второй низкоинтенсивный пик при температуре $\sim 50^{\circ} \mathrm{C}$ обусловлен наличием в полимере несовершенных и дефектных кристаллитов, образованных не стереорегулярными макромолекулами.

Благодарность/Acknowledgements. Авторь благодарят Глазырина А.Б. (БашГУ) за помощь в проведении
ДСК экспериментов. ИПД КВД полимерных образиов проведена при поддержке гранта РНФ (проект 14-12-00138). В экспериментальных исследованиях использовалось оборудование ЦКП Спектр ИФМК УНЦ РАН.

\section{Литература/References}

1. http://www.jsr.co.jp/jsr_e/pd/tpe_rb.shtml

2. Y. Obata, C. Tosaki, M. Ikeyama Polymer J. 7, 207 (1975).

3. Y. Obata, C. Homma, C. Tosaki, N. Shiraishi Polymer J., 7, 217 (1975).

4. Y. Chen, D. Yang, Y. Hu, X. Zhang Cryst. Growth and Design. 4, 117 (2004).

5. B. Wunderlich Macromolecular Physics: Crystal structure, morphology, defects. N.Y. Academic Press, 1973, 592 р. [Б. Вундерлих Физика макромолекул. Кристаллическая структура, морофология, дефекты. М.: Мир, 1976. 574 с.]

6. A. Galeski; A. S. Argon, R. E. Cohen, Macromolecules 24, 3953 (1991).

7. L. Lin, A.S. Argon J. Mater. Sci. 29, 294 (1994).

8. R. Seguela Polymer Rev., 45 (3), 263 (2005).

9. R.Z. Valiev, I. V. Alexandrov Bulk nanostractured materials: production, structure and properties M.: Academkniga, 2007, 398 p. (in Russian) [Р.3. Валиев, И.В. Александров. Объемные наноструктурные материалы: получение, структура и свойства. М.: ИКЦ «Академкнига», 2007. 398c.]

10. Z. S. Mo, H. F. Zhang Polym. Rev., 35, 555 (1995)

11. A.N. Chuvyrov, R.R. Kinzyabulatov, Yu. A. Lebedev, A. B. Glazyrin, R. K. Teregulov Deformation and fracture of materials № 9, 29 (2009) (in Russian) [Чувыров А.Н., Кинзябулатов Р.Р., Лебедев Ю.А., Глазырин А.Б., Терегулов Р.К. Деформация и разрушение материалов, № 9, 29 (2009)].

12. A.N. Chuvyrov, R.R. Kinzyabulatov, Yu.A. Lebedev Doklady Chemistry, 437 (2), 124 [А.Н. Чувыров, Р. Р. Кинзябулатов, Ю.А. Лебедев Доклады РАН, 437, 659 (2011)].

13. G. Natta, P. Corradini J. Polymer Sci. 20, 251 (1956).

14. A.R. Khamidullin, A.N. Chuvyrov, Yu. A. Lebedev, V.D. Sitdikov Moscow Univ. Phys. Bull., 68, 225 (2013) [А.Р. Хамидуллин, А.Н. Чувыров, Ю.А. Лебедев, В. Д. Ситдиков, Вестник МГУ. Сер.3 Физика, астрономия, № 3, 47 (2013)].

15. V.A. Bernshtain, V.M. Egorov Differential scanning calorimetry in physico-chemistry of polymers (in russian) L.: Khimiya, 1990, 256 c. [В. А. Бернштейн, В. М. Егоров Дифференциальная сканирующая калориметрия в физикохимии полимеров. Л.: Химия, 1990. 256 с.]

16. M. Ren, Q. Chen, J. Song, H. L. Zhang, X. Sun, J. Polymer Science: B: Polym. Phys. 43, 553 (2005)

17. R. Napolitano, B. Pirozzi, S. Esposito Macromol. Chem. Phys. 207, 503 (2006).

18. Lima M. F. S., Vasconcellos M. A. Z., Samios D. J. Polym. Sci. B: Polym. Phys., 40, 896 (2002)

19. F. Auriemma C. De Rosa, P. Corradini Adv. Polym.Sci. $181,1(2005)$ 